\title{
Analisa Tingkat Kesehatan Bank Berdasarkan Pendekatan RBBR (Risk Based Bank Rating) Pada PT. Bank SulutGo Periode 2015-2018
}

\author{
Jek Malensang \\ Dolina L. Tampi \\ W. S. Manoppo \\ Jurusan Ilmu Administrasi, Program Studi Administrasi Bisnis \\ Fakultas Ilmu Sosial dan Ilmu Politik, Universitas Sam Ratulangi \\ jekmalensang@gmail.com
}

\begin{abstract}
To find out how the bank's health conditions are valued using the RBBR Risk-Based Bank Rating method at PT. Bank SulutGo Manado. The Bank is the financial institutions that have a major role gather funds from the community in the form of savings and distributing the funds to the community in the form of credit with the purpose of improving the community standard of living. This research uses the factor Risk-Based Bank Rating, Factors risk profile, credit risk using the ratio of Net Performing Loan (NPL), market risk by using a ratio Interest Rate Risk (IRR), and liquidity risk by using the ratio of the Loan to Deposit Ratio (LDR). This study shows that Good Corporate Governance (GCG) factors change in each period because the results of the calculation ratios that exist in these factors indicate developments in 2017 and 2018 in the healthy category means that the company is able to overcome the problems that occurred in previous years. Research on the factor risk profile shows that the bank owned by the local government has the average NPL 0,86\%, IRR 205,4\%, LDR 101,09\%. The evaluation comprises ratio ROA and NIM shows the average bank rentabilitas belongs to the local government is very adequate for bank capital. The results of the assessment ratio of the CAR shows the entire predicated very healthy that indicates the bank is able to fulfill the obligation of providing the capital.
\end{abstract}

Keywords: The Level Of Health Risk Of Banks, Risk Based Bank Rating Method (RBBR)

\section{Pendahuluan}

Bank adalah lembaga keuangan yang memiliki peran utama menghimpun dana dari masyarakat dalam bentuk simpanan dan menyalurkan kembali dana kepada masyarakat dalam bentuk kredit dengan tujuan meningkatkan taraf hidup masyarakat. Pada tanggal 5 Januari 2011, kebijakan penilaian tingkat kesehatan bank tersebut kembali diperbarui oleh Bank Indonesia dengan mengeluarkan Peraturan
Bank Indonesia No. 13/PBI/2011. Peraturan ini adalah penyempurnaan dari metode CAMELS disebut dengan metode Risk Based Bank Rating (RBBR). Metode RBBR terdiri dari beberapa faktor yaitu Risk Profile, Good Corporate Governance (GCG), Earning, and Capital. (risk profile) faktor utama yang menjadi dasar dalam penilaian tingkat kesehatan bank dengan metode RBBR. Rasio yang digunakan dalam menunjukkan kinerja profil risiko 
yaitu Non Performing Loan (NPL), Interest

Rate Risk (IRR) dan Loan to Deposit Ratio

(LDR). Faktor kedua yang menjadi dasar penilaian adalah Good Corporate Governance (GCG) Prinsip-prinsip dasar GCG yaitu akuntabilitas, transparansi, pertanggungjawaban, ke-wajaran dan kemandirian. Rasio rentabilitas yang dapat digunakan dalam menunjukkan kinerja rentabilitas adalah Return on Asset (ROA) dan Net Interest Margin (NIM). Faktor yang terakhir adalah faktor modal (Capital). Modal memiliki peran yang sangat penting, dimana modal memiliki peran sebagai sumber pendukung keuangan dalam aktivitas bank apa bilah bank mengalami kerugian yang tak terduga dalam menjalankan kegiatan operasionalnya.

\section{Bank}

Menurut Sulhan dalam Suhartono (2017). Bank adalah lembaga yang memiliki peran dasar sebagai "intermediasi” antara pemilik dana (surplus spending unit) dan peminjam dana (deficit spending unit) sehingga bank memiliki produk dasar dan utama berupa simpanan dan pinjaman.

Menurut Taswan (2010) Bank adalah sebuah lembaga atau perusahaan yang aktivitasnya menghimpun dana berupa giro, deposito, tabungan dan simpanan yang lain dari pihak yang kelebihan dana kemudian menempatkannya kembali kepada masyarakat yang membutuhkan dana melalui penjualan jasa keuangan yang pada gilirannya dapat meningkatkan kesejahteraan rakyat banyak. Sedangkan menurut Kasmir (2012) Bank adalah lembaga keuangan yang kegiatan utamanya menghimpun dana dari masyarakat dan menyalurkan kembali dana tersebut ke masyarakat serta memberikan jasa-jasa bank lainnya.

\section{Kesehatan Bank}

Menurut Supriyanto dalam Suhartono (2017). Menilai suatu kesehatan bank dapat dilihat dari berbagai segi. Penilaian ini bertujuan untuk menentukan apakah bank tersebut dalam kondisi yang sehat, cukup sehat, kurang sehat, dan tidak sehat. Bagi bank yang sehat agar tetap mempertahankan kesehatannya, sedangkan bank yang sakit untuk segera mengobati penyakitnya. Bank Indonesia sebagai pengawas dan pembina bank-bank dapat memberikan arahan atau petunjuk bagaimana bank tersebut harus dijalankan atau bahkan jika perlu dihentikan kegiatan operasinya. "Kelangsungan usaha industri perbankan sangat ditentukan oleh nasabahnya. Sementara loyalitas nasabah sangat ditentukan oleh aspek kepercayaan nasabah kepada bank pilihannya. Dengan 
demikian, unsur kepercayaan masyarakat terhadap industri perbankan merupakan kunci keberhasilan dan kelangsungan usaha-usaha bank.

Berdasarkan dari UU Nomor 10 Tahun 1998, secara garis besar tujuan perbankan Indonesia adalah menunjang pelaksanaan pembangunan nasional dalam rangka meningkatkan pemerataan, pertumbuhan ekonomi, dan stabilitas nasional ke arah peningkatan kesejahteraan rakyat. Dari tujuan tersebut maka perbankan (bank) di Indonesia harus menjalankan tugas dan fungsinya dengan baik dan didasarkan atas asas demokrasi ekonomi.

Laporan keuangan adalah hasil akhir proses akuntansi. Setiap transaksi yang dapat diukur dengan nilai uang, dicatat dan di olah sedemikian rupa. Laporan akhir pun disajikan dalam nilai uang. Transaksi yang tidak dapat dicatat dengan nilai uang, tidak akan terlihat dalam laporan keuangan. Karena itu hal-hal yang belum terjadi dan masih berupa potensi, tidak tercatat dalam laporan keuangan. Dengan demikian, laporan keuangan merupakan informasi historis.

\section{Metode Penelitian}

Jenis penelitian yang digunakan adalah penelitian deskriptif dengan pendekatan kuantitatif. Berdasarkan uraian tersebut disimpulkan bahwa penelitian deskriptif dengan pendekatan kuantitatif adalah penelitian terhadap suatu objek untuk memuat deskripsi dan gambaran sistematis mengenai fakta-fakta objek yang diteliti, dengan menggunakan data berupa angka sebagai alat untuk menganalisis. Penelitian kuantitatif harus disusun secara teliti, detail, dan sistematis mengenai penjabaran angka-angka dari suatu data.

\section{Metode Pengumpulan Data}

Berdasarkan metode pengumpulan data yang digunakan pada penelitian ini adalah teknik pengumpulan data dengan cara dokumentasi. Dokumentasi adalah "catatan peristiwa yang telah berlalu. Dokumen ini dapat berupa tulisan atau karya-karya monumental dari seseorang" (Sugiyono,2010). Dokumentasi yang digunakan dalam penelitian ini berupa data keuangan adapun dalam bentuk wawancara dilakukan pada PT Bank SulutGo Cabang Manado, dengan melakukan Tanya jawab secara langsung dan mengambil data keuangan dari pihak yang berwenang atau pihak lain yang berhubungan dengan objek yang diteliti untuk mendapatkan informasi secara jelas tentang tingkat kesehatan keuangan bank melalui website resmi Bank SulutGo.

Serta ada pula dalam bentuk observasi yang dilakukan penulis melalui pengamatan langsung kelapangan dengan 
cara mencatat segala yang ditemukan dan dapat dijadikan data atau bahan penulisan skripsi yang berhubungan dengan tingkat kesehatan keuangan bank.

\section{Hasil Penelitian dan Pembahasan}

\section{Analisis Data}

\section{Risk Profil (Profil Resiko)}

a) Non-Performing Loan

Rasio NPL dapat menunjukan kemampuan bank dalam mengelola kredit bermasalah dari keseluruhan kredit yang diberikan oleh bank. Rasio NPL diperoleh dari kredit bermasalah yaitu merupakan kredit kepada pihak ketiga bukan bank yang tergolong kurang lancar, pihak ketiga bukan bank.

Tabel Kesehatan Bank SulutGo berdasarkan rasio NPL

\begin{tabular}{|c|c|c|c|}
\hline Tahun & Nilai & Peringkat & Predikat \\
\hline 2015 & $0,53 \%$ & 1 & Sangat sehat \\
\hline 2016 & $0,61 \%$ & 1 & Sangat sehat \\
\hline 2017 & $1,12 \%$ & 1 & Sangat sehat \\
\hline 2018 & $1,18 \%$ & 1 & Sangat sehat \\
\hline
\end{tabular}

Sumber: Data Olahan, 2019

\section{b) Interest Rate Risk}

Rasio IRR adalah rasio pada posisi neraca dan rekening administratif termasuk transaksi derivative, akibat perubahan secara keseluruhan dari kondisi pasar, termasuk perubahan atau pergerakan variabel pasar, tingkat suku bunga, kurs valuta asing, saham, dan komoditi. Berikut hasil perhitungan rasio IRR Bank SulutGo periode 2015-2018.

Tabel Kesehatan Bank SulutGo berdasarkan rasio IRR

\begin{tabular}{cccc}
\hline Tahun & Nilai & Peringkat & Predikat \\
\hline 2015 & $98,52 \%$ & 1 & Sangat sehat \\
2016 & $231,27 \%$ & 1 & Sangat sehat \\
2017 & $251,84 \%$ & 1 & Sangat sehat \\
2018 & $240,30 \%$ & 1 & Sangat sehat \\
\hline
\end{tabular}

Sumber: Data Olahan, 2019

\section{c). Loan to Deposito Ratio}

Rasio LDR merupakan perbandingan antara total kredit dengan dana pihak tiga bukan bank yang terdiri dari tabungan, giro dan deposito berjangka. Rasio LDR digunakan untuk mengukur perbandingan jumlah total kredit yang diberikan bank dengan dana pihak ketiga, yang menggambarkan kemampuan bank dalam membayar kembali penarikan dana oleh masyarakat dengan mengandalkan kredit yang diberikan sebagai sumber likuiditasnya. Berikut hasil perhitungan rasio LDR Bank SulutGo periode 20152018.

Tabel Kesehatan Bank SulutGo berdasarkan rasio LDR

\begin{tabular}{cccc}
\hline Tahun & Nilai & Peringkat & Predikat \\
\hline 2015 & $100,19 \%$ & 1 & Sangat sehat \\
2016 & $101,00 \%$ & 1 & Sangat sehat \\
2017 & $101,48 \%$ & 1 & Sangat sehat \\
2018 & $101,72 \%$ & 1 & Sangat sehat \\
\hline Sumber:
\end{tabular}

Sumber: Data Olahan, 2019

Good Corporate Governance (GCG)

Pemberian kriteria GCG dilakukan oleh bank secara self-assessment namun 
tetap dalam pengawasan Bank Indonesia. self-assessment merupakan penilaian sendiri terhadap masing-masing bank atas persetujuan dewan direksi dengan mengacu peringkat komposit pada SE BI No.15/15 DPNP tahun 2013. Berikut hasil selfassessment yang dilakukan oleh Bank SulutGo tahun 2015-2018.

Tabel Kesehatan Bank SulutGo berdasarkan rasio GCG

\begin{tabular}{ccc}
\hline Tahun & Peringkat & Predikat \\
\hline 2015 & 3 & Cukup sehat \\
2016 & 4 & Kurang Baik \\
2017 & 2 & Sehat \\
2018 & 2 & Sehat
\end{tabular}

Sumber: Data Olahan, 2019

Earnings (Rentabilitas)

\section{a) Return On Asset}

Merupakan rasio profitabiltas yang mampu menunjukan keberhasilan suatu bank dalam menghasilkan keuntungan atau laba dengan mengoptimalkan asset yang dimiliki. Semakin kecil rasio ini berarti manajemen bank kurang mampu dalam mengelola asset untuk meningkatkan pendapatan dan menekan biaya. Berikut hasil perhitungan rasio ROA Bank SulutGo periode 2015-2018.

Tabel Kesehatan Bank SulutGo berdasarkan rasio $\mathrm{ROA}$

\begin{tabular}{cccc}
\hline Tahun & Nilai & Peringkat & Predikat \\
\hline 2015 & $1,75 \%$ & 1 & Sangat sehat \\
2016 & $2,28 \%$ & 1 & Sangat sehat \\
2017 & $2,78 \%$ & 1 & Sangat sehat \\
2018 & $2,40 \%$ & 1 & Sangat sehat \\
\hline
\end{tabular}

Sumber: Data Olahan, 2019 b) Net Interest Margin

Rasio ini digunakan sebagai alat ukur untuk mengetahui tingkat rentabilitas bank yang diperoleh dari pendapatan bunga bersih atas aktiva-aktiva produktif atau aktiva yang menghasilkan bunga bersih dibagi rata-rata asset produktif. Berikut hasil perhitungan rasio NIM Bank SulutGo periode 2015-2018.

Tabel Kesehatan Bank SulutGo berdasarkan rasio NIIM

\begin{tabular}{cccc}
\hline Tahun & Nilai & Peringkat & Predikat \\
\hline 2015 & $8,43 \%$ & 1 & Sangat sehat \\
2016 & $8,91 \%$ & 1 & Sangat sehat \\
2017 & $8,25 \%$ & 1 & Sangat sehat \\
2018 & $7,71 \%$ & 1 & Sangat sehat \\
\hline
\end{tabular}

Sumber: Data Olahan, 2019

Capital (Permodalan)

Rasio keuangan yang digunakan dalam menilai tingkat kesehatan Bank SulutGo ditinjau dari aspek capital pada penelitian ini adalah Capital Adequacy Ratio (CAR). Rasio CAR digunakan untuk mengukur kecukupan modal yang dimilki bank untuk menunjang aktiva yang mengandung atau menghasilkan resiko. Berikut hasil perhitungan rasio CAR Bank SulutGo periode 2015-2018.

Tabel Kesehatan Bank SulutGo berdasarkan rasio CAR

\begin{tabular}{cccc}
\hline Tahun & Nilai & Peringkat & Predikat \\
\hline 2015 & $14,35 \%$ & 1 & Sangat sehat \\
2016 & $17,10 \%$ & 1 & Sangat sehat \\
2017 & $16,61 \%$ & 1 & Sangat sehat \\
2018 & $16,48 \%$ & 1 & Sangat sehat \\
\hline
\end{tabular}

Sumber: Data Olahan, 2019 


\section{Pembahasan}

Risk Profil (Resiko Profil)

Rasio keuangan yang digunakan dalam menilai tingkat kesehatan Bank SulutGo ditinjau dari aspek risk profil pada penelitian ini dengan menggunakan 3 indikator yaitu resiko kredit dengan menggunakan rumus NPL Nilai rasio NPL yang semakin kecil menunjukkan bahwa bank semakin baik dalam menyeleksi calon peminjam sehingga jumlah kredit yang tergolong kurang lancar, diragukan dan macet pun berkurang, resiko pasar dengan menggunakan rumus IRR Nilai rasio IRR yang semakin besar menunjukkan bahwa bank semakin baik dalam mengatur proses administratif sehingga ketika terjadi perubahan dalam kondisi pasar maka Bank mampu mengatasi masalah yang terjadi sehingga bank dapat dikategorikan cukup baik, dan resiko likuiditas dengan rumus LDR Secara keseluruhan sebaiknya Bank SulutGo perlu mengetatkan jumlah kredit yang disalurkan dan tetap menjaga prinsip kehati-hatian di tahun mendatang, dilihat dari nilai LDR tahun 2015-2018 berada dalam kondisi kurang sehat.

\section{Good Corporate Governance (GCG)}

Penerapan GCG yang baik akan meningkatkan kepercayaan stakeholder untuk melakukan transaksi pada Bank SulutGo, karena melihat nilai GCG Bank
SulutGo tahun 2015-2018 terjadi perubahan setiap tahunnya, maka stakeholder dapat menge-tahui resiko apa yang mungkin terjadi apabila melakukan transaksi dengan bank tersebut Tingkat kesehatan yang tiap tahunnya meng-alami perubahan dilihat dari GCG pada Bank SulutGo berada di kategori sehat pada tahun 2017 dan 2018.

\section{Earnings (Rentabilitas)}

Rasio keuangan yang digunakan dalam menilai tingkat kesehatan Bank SulutGo dilihat dari aspek Earnings pada penelitian ini dengan menggunakan dua indikator yaitu menggunakan rumus ROA Nilai ini me-nyatakan bahwa ROA Bank SulutGo mengalami fluktuasi namun tidak mem-berikan dampak yang negatif karena berada pada kategori sehat, yang artinya hal ini menunjukan bahwa kemampuan bank dalam memperoleh laba dengan mengandalkan asetnya telah berjalan denga sebaik mungkin. Dan NIM nilai rasio ini mengalami penurunan, hal ini disebabkan oleh kenaikan suku bunga sehingga menyebabkan tingginya biaya bunga yang di tanggung oleh bank. Namun secara keseluruhan nilai tersebut menunjukan kemampuan bank dalam memperoleh pendapatan bunga bersih selama tiga tahun sudah sangat baik dan masuk dalam kategori sangat sehat, sehingga dapat disimpulkan kemampuan manajemen 
dalam mengelola aktiva produktifnya untuk menghasilkan pendapatan bunga bersih perusahaan sangat baik.

\section{Capital (Permodalan)}

CAR yang besar menunjukan bahwa bank dapat menyangga kerugian operasional bila terjadi dan dapat mendukung pemberian kredit yang besar. CAR yang besar juga dapat meningkatkan kepercayaan dari masyarakat untuk menyalurkan dananya ke Bank SulutGo Nilai CAR yang dimiliki Bank SulutGo selama tiga periode tersebut berada diatas standar yang telah di tetapkan sehingga bank dinilai telah mampu memenuhi kewajiban penyedia modal minimum.

\section{Kesimpulan}

Hasil Penilaian tingkat kesehatan Bank SulutGo dilihat dari aspek penilaian dengan metode RBBR selama tahun 20152018 menempati Peringkat komposit 1 (PK-1). Selama periode tersebut Bank SulutGo dinilai sangat mampu menghadapi pengaruh negatif yang signifikan dari perubahan kondisi bisnis dan faktor eksternal lainnya dilihat dari kriteria penilaian faktor-faktor, antara lain risk profil, good corporate governance, earnings, dan capital yang secara umum sangat baik. Apabila terdapat kelemahan maka secara umum kelemahan tersebut dapat di atasi secara signifikan oleh perusahaan.

\section{Saran}

Berdasarkan dari data yang telah di peroleh dan telah disimpulkan maka Sebaiknya pihak manajemen bank lebih selektif dan lebih memperhatikan dalam pemberian kredit terhadap nasabah dan mengikuti peraturan perkreditan yang berlaku dan telah ditetapkan oleh Bank Indonesia untuk menghindari terjadinya kredit macet. Dari segi aspek likuiditas Bank SulutGo yang memiliki rasio LDR yang melebihi batas maksimal dari ketentuan yang telah ditetapkan oleh Bank Indonesia sebaiknya untuk lebih memperhatikan seluruh kewajiban bank terlebih khusus kewajiban jangka pendek dan berusaha untuk menyeimbangkan antara pemberi kredit dengan banyaknya dana yang diterima dari pihak ketiga agar likuiditas bank dapat terjaga.

\section{Daftar Pustaka}

Kasmir. 2012. Manajemen Perbankan. Jakarta : PT Raja Grafindo persada.

Sugiyono. 2010, Metode Penelitian Kuantitatif Kualitatif dan $R \& D$; Penerbit CV Alfabeta, Bandung

Suhartono, (2017) Analisa Tingkat Kesehatan Bank Dengan Menggunakan Metode Risk Based Bank Rating. Jurnal Administrasi 
Bisnis. Malang: Universitas

Brawijaya. Volume. 46 (2017)

Taswan. 2010. Manajemen Perbankan, Konsep, Teknik, dan Aplikasi. Edisi kedua. Yogyakarta : UPP STIM YKPN.

\section{Sumber lain:}

Bank Indonesia. 2011. Peraturan Bank Indonesia Nomor: 13/1/PBI/2011

5 Januari 2011 tentang Penilaian Tingkat Kesehatan Bank. Umum

Surat Edaran Bank Indonesia Nomor 13/24/DNPN 25 Oktober 2011

tentang Penilaian Tingkat Kesehatan Bank Umum. 